\title{
Indications of the Mechanisms Involved in Improved Sperm Parameters by Zinc Therapy
}

\author{
A.E. Omu ${ }^{a}$ M.K. Al-Azemi ${ }^{a}$ E.O. Kehinde ${ }^{b}$ J.T. Anim ${ }^{c}$ M.A. Oriowo ${ }^{d}$ \\ T.C. Mathew ${ }^{\mathrm{e}}$

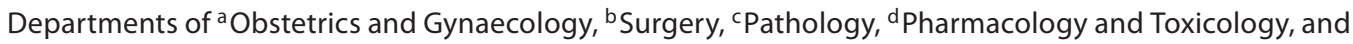 \\ ${ }^{\mathrm{e}}$ Anatomy (Electron Microscopy Unit), Faculty of Medicine, Health Sciences Centre, Kuwait University, Kuwait
}

\section{Key Words}

Asthenozoospermia $\cdot$ Zinc therapy $\cdot$ Modulation •

Sperm DNA

\begin{abstract}
Objective: To determine possible indications of the mechanisms involved in improved sperm parameters by zinc therapy in asthenozoospermic men. Subjects and Methods: Forty-five men with asthenozoospermia ( $\geq 40 \%$ immotile sperm) were randomized into four therapy groups: zinc only: $\mathrm{n}=11 ;$ zinc + vitamin $\mathrm{E}: \mathrm{n}=12$ and zinc + vitamins $\mathrm{E}+\mathrm{C}$ : $\mathrm{n}=14$ for 3 months, and non-therapy control group: $\mathrm{n}=8$. Semen analysis was done according to WHO guidelines. Malone dialdehyde, tumour necrosis factor- $\alpha$ (TNF- $\alpha)$, total antioxidant capacity, superoxide dismutase (SOD) and glutathione peroxidase were determined in the semen and serum. Antisperm antibodies IgG, IgM and IgA were evaluated by immunobeads. Sperm chromatin integrity was determined by acid denaturation by acridine orange and sperm apoptosis by light and electron microscopy. The effect of zinc on in vitro induced sperm oxidative stress by NADH was evaluated. Results: Asthenozoospermia was significantly associated with oxidative stress with higher seminal malone dialdehyde ( 8.8 vs. $1.8 \mathrm{mmol} / \mathrm{l}, \mathrm{p}<0.001)$ and TNF- $\alpha$ (60 vs. $12 \mathrm{pg} / \mathrm{l}, \mathrm{p}<0.001$ ), and low total antioxidant capacity (1.8 vs. $8.4, p<0.01)$, SOD $(0.8$ vs. $3.1, p<0.01)$ and glutathione per-
\end{abstract}

oxidase (1.6 vs. 4.2, p<0.05), compared to normozoospermia. Zinc therapy alone, in combination with vitamin $\mathrm{E}$ or with vitamin $\mathrm{E}+\mathrm{C}$ were associated with comparably improved sperm parameters with less oxidative stress, sperm apoptosis and sperm DNA fragmentation index (DFI). On the whole, there was no difference in the outcome measures between zinc only and zinc with vitamin $E$ and combination of vitamins $E+C$. In the in vitro experiment zinc supplementation resulted in significantly lower DFI $(14-29 \%, p<0.05)$ compared to zinc deficiency. Conclusion: Zinc therapy reduces asthenozoospermia through several mechanisms such as prevention of oxidative stress, apoptosis and sperm DNA fragmentation.

Copyright $\odot 2008$ S. Karger AG, Basel

\section{Introduction}

Asthenozoospermia is a common disorder of sperm motility which gives rise to male factor infertility. The aetiology involves oxidative stress from production of free radicals by abnormal spermatozoa with residual cytoplasm, leucocytospermia, seminal infection and proinflammatory cytokines [1]. Both smoking and seminal antisperm antibodies are also causes of increased reactive oxygen species production in semen and therefore contribute to oxidative stress [2-4]. The end result is lower

\section{KARGER}

Fax +4161306 1234 E-Mail karger@karger.ch www.karger.com
(C) 2008 S. Karger AG, Basel

1011-7571/08/0172-0108\$24.50/0

Accessible online at:

www.karger.com/mpp
Dr. Alexander E. Omu, FRCOG

Department of Obstetrics and Gynaecology, Faculty of Medicine

HSC, Kuwait University, PO Box 24923

13110 Safat (Kuwait)

Tel. +965 498 6458, Fax +965 533 8906, E-Mail Omu@hsc.edu.kw 
sperm counts, impaired sperm motility, defective sperm structure and reduced sperm movement [5]. Oxidative stress occurs commonly in spermatozoa through lipid peroxidation because the sperm membrane contains high amounts of polyunsaturated fatty acids. The concept of improving fertility potential of infertile patients with oxidative stress by certain antioxidants has gained considerable attention in assisted reproductive technology and infertility practice $[6,7]$. Spermatozoa depend on scavenging systems provided by the seminal plasma, with important natural antioxidants such as vitamins $\mathrm{C}$ and $\mathrm{E}$, superoxide dismutase and glutathione and thioredoxin that act directly as free radical scavengers $[8,9]$. We had previously reported that zinc therapy in men with asthenozoospermia resulted in significant improvement in sperm quality with increases in sperm concentration, progressive motility, sperm integrity and improved conception and pregnancy rates [3]. A combination treatment of zinc and folic acid improved overall sperm count in subfertile men by $74 \%$ but the mechanisms involved have not been elucidated [10]. A recent study has shown that the increase in sperm concentration after zinc and folic acid is not a result of endocrine alterations, in follicle-stimulating hormone, testosterone or inhibin [11]. Therefore, the objective of this study was to evaluate possible mechanisms involved in the role of zinc therapy in the improvement of sperm parameters in men with asthenozoospermia.

\section{Subjects and Methods}

Forty-five men attending the combined-infertility clinic at the Maternity Hospital, Kuwait, were recruited for the study after approval of the Institutional Ethics Committee and informed consent were obtained.

The inclusion criteria were men with asthenozoospermia with normal sperm concentration of 20-250 million/ml, but $40 \%$ or more of the spermatozoa in the semen sample were immotile. All men with asthenozoospermia but with sperm concentration of less than 20 million/ml were excluded from the study.

The 45 asthenozoospermic men were randomized into four groups: (a) 11 men with zinc sulphate $200 \mathrm{mg}$ twice daily, (b) 12 men with zinc sulphate $200 \mathrm{mg}+$ vitamin E $10 \mathrm{mg}$ twice daily, (c) 14 men with zinc sulphate $200 \mathrm{mg}+$ vitamin E $10 \mathrm{mg}+$ vitamin C 5 mg twice daily, all for 3 months, (d) 8 men served as nontherapy control. Evaluation of sperm parameters was at initial pre-therapy, after 6 weeks and at the end of therapy after 3 months. 12].

Semen analysis was carried out according to WHO guidelines

The sperm membrane integrity was assessed with hypo-osmotic swelling test as previously described [3]. The remaining semen was centrifuged at $850 \mathrm{~g}$ for $10 \mathrm{~min}$ and the supernatant sem- inal plasma was stored at $-20^{\circ} \mathrm{C}$ in $0.1-\mathrm{ml}$ aliquots, until used for assays. The sperm residue was used for the evaluation of the sperm morphology and integrity.

Assay of Trace Elements. For serum trace analysis, $10 \mathrm{ml}$ of venous blood was collected from each patient in metal-free tubes (Becton-Dickinson, New Jersey), serum was separated and analysed for trace metal content by graphite furnace atomic absorption spectrophotometer as described previously [13].

Assays of Oxidants, Cytokines and Antioxidants. Malone dialdehyde was assayed in serum and seminal plasma as previously described [14]. Antioxidants like superoxide dismutase, glutathione peroxidase, total antioxidant capacity and tumour necrosis factor- $\alpha$ (TNF- $\alpha$ ) and interleukin-4 (IL-4) were evaluated by ELISA as previously described [5].

Bcl-2 and Bax Expression Level Estimation by ELISA Technique. A 96-well kit was used. A standard curve was first created with different concentrations of the standard of Bcl-2 or Bax. Samples and standard were pipetted in duplicates into the wells and incubated at $4^{\circ} \mathrm{C}$ for about $1 \mathrm{~h}$, monoclonal antibody was then added and incubated for another $30 \mathrm{~min}$. After further incubation for $30 \mathrm{~min}$ with the conjugate, the substrate was pipetted into the wells, incubated for further $30 \mathrm{~min}$ and the stop solution was added and read on a plate reader at $450 \mathrm{~nm}$.

Antisperm Antibodies IgG, IgM and IgA. Antisperm antibodies were evaluated by immunobeads as previously described [15] with anti-immunoglobulin beads (Labsystems AB, Sweden). The percentage total binding any bead on the sperm surface $=$ number of sperm with bound beads/total number of sperm counted.

Effect of Zinc Deficiency on Sperm DNA: An in vitro StudySperm Preparation, Acridine Orange Staining Sperm Chromatin Structural Assay. Sperm chromatin structure assay was used to measure the susceptibility of sperm DNA to acid-induced denaturation by acridine orange as described by Evenson and Jost [16]. Briefly, after centrifugation for $5 \mathrm{~min}$ at $600 \mathrm{~g}$, the sediment containing spermatozoa was washed twice with Roswell Park Memorial Institute medium, and maintained under subconfluent conditions with $10 \%$ fetal serum in the absence and presence of zinc supplementation $(20 \mathrm{mM}$ of $\mathrm{ZnCl})$. An unprocessed semen sample served as control. To the three groups $5 \mathrm{mM}$ of NADH was added for the endogenous generation of oxidative stress as previously described by Aitken et al. [17], and incubated for $2-4 \mathrm{~h}$ at $4{ }^{\circ} \mathrm{C}$. Thereafter, the sperm preparation was centrifuged at $1,200 \mathrm{~g}$ for $10 \mathrm{~min}$ and the sediment was used for sperm chromatin structure assay by mixing it with a drop of acridine orange for $30 \mathrm{~min}$ and examined with fluorescence microscopy. Three hundred spermatozoa were counted in each sample.

Hematoxylin and Eosin (HE) Staining. HE staining was performed using standard techniques for Cole's hematoxylin. Apoptotic cells were identified under a light microscope using the following morphological criteria: intense, uniform nuclear basophilia with either chromatin condensation and nuclear shrinkage or fragmentation of the nucleus into several rounded and uniformly densely basophilic masses.

Electron Microscopy of Spermatozoa. The spermatozoa was washed 3 times with phosphate buffer $(0.1 \mathrm{~mol} / \mathrm{l}, \mathrm{pH} 7.4)$ and fixed in $3 \%$ glutaraldehyde followed with $1.3 \%$ osmium tetroxide. The sections were then examined and photographed with a Zeiss 109 Electron Microscope (Zeiss Oberkochen, Germany). At least 100 sperm flagella were counted for quantification of axonemal anomalies as described by Olmedo et al. [18]. 
Table 1. Characteristics of men with asthenozoospermia compared with normozoospermia and oligozoospermia

\begin{tabular}{lccc}
\hline & $\begin{array}{l}\text { Oligozoospermia } \\
(\mathrm{n}=12)\end{array}$ & $\begin{array}{l}\text { Asthenozoospermia } \\
(\mathrm{n}=45)\end{array}$ & $\begin{array}{l}\text { Normozoospermia } \\
(\mathrm{n}=14)\end{array}$ \\
\hline Age, years & $35 \pm 6$ & $35 \pm 1$ & $34 \pm 9$ \\
Duration of infertility & $5.6 \pm 3.2$ & $5.5 \pm 3.1$ & $4.8 \pm 2.4$ \\
Smoking habits & 5 & & 6 \\
$\quad$ Smoking & 7 & 20 & 8 \\
$\quad$ Non-smoking & & 25 & $3.5 \pm 0.8$ \\
Semen parameters & $3.2 \pm 1.1$ & $3.5 \pm 1.4$ & $58.4 \pm 24.8$ \\
$\quad$ Semen volume, ml & $12 \pm 8^{\mathrm{a}}$ & $45.6 \pm 22.4$ & $62.6 \pm 20.4$ \\
$\quad$ Sperm concentration, million/ml & $38.6 \pm 26.4$ & $25.4 \pm 11.2^{\mathrm{b}}$ & $75 \pm 18$ \\
$\quad$ Motility, \% & $66 \pm 16$ & $70 \pm 15$ & $62 \pm 22$ \\
$\quad$ Normal morphology, \% & $42 \pm 32$ & $38 \pm 28^{\mathrm{c}}$ & \\
Fertilizing capacity, \% (HOS) & & & \\
\hline
\end{tabular}

HOS = Hypo-osmotic swelling test.

${ }^{a}$ Oligozoospermia vs. asthenozoospermia, $\mathrm{p}<0.05$; oligozoospermia vs. normozoospermia, $\mathrm{p}<0.05$.

${ }^{\mathrm{b}}$ Asthenozoospermia vs. oligozoospermia, $\mathrm{p}<0.05$; vs. normozoospermia, $\mathrm{p}<0.01$.

${ }^{c}$ Asthenozoospermia vs. normozoospermia, $\mathrm{p}<0.05$.

Statistical Analysis. Data were analysed with Statview software. The mean \pm SD was calculated for paired values. Differences within groups were estimated by the non-parametric MannWhitney test for continuous measurements of observation from the same distribution like levels of sperm parameters, antioxidants, Bcl-2 and Bax at weeks 0, 6 and 12. ANOVA and linear regression analysis were used when appropriate. Statistically significant $\mathrm{p}$ value was accepted at $\mathrm{p}=0.05$.

\section{Results}

The characteristics of men with asthenozoospermia compared with those with oligozoospermia and normozoospermia as shown in table 1 . The sperm motility and sperm membrane integrity were significantly reduced in asthenozoospermia compared to oligozoospermia ( $\mathrm{p}<$ 0.05 ) and normozoospermia $(\mathrm{p}<0.01)$. Higher titre of antisperm antibodies, especially IgG, were more commonly associated with asthenozoospermia and oligozoospermia than with normozoospermia $(\mathrm{p}<0.05)$ as shown in table 2 . The antiapoptotic protein Bcl-2 was more highly expressed in normozoospermia $(\mathrm{p}<0.05)$ than in oligozoospermia and asthenozoospermia whereas the pro-apoptotic Bax was more highly expressed in men with oligozoospermia and asthenozoospermia $(\mathrm{p}<$ 0.05). The seminal trace elements did not show any differences between asthenozoospermic men and the controls.
Table 2. Association between sperm parameters, oxidative stress and antioxidant status

\begin{tabular}{lccc}
\hline & $\begin{array}{l}\text { Oligo- } \\
\text { zoospermia }\end{array}$ & $\begin{array}{l}\text { Astheno- } \\
\text { zoospermia }\end{array}$ & $\begin{array}{l}\text { Normo- } \\
\text { zoospermia }\end{array}$ \\
\hline Oxidative stress & & & \\
$\quad$ MDA, nmol/l & $6.4 \pm 3.2$ & $8.8 \pm 3.4^{\mathrm{a}}$ & $1.8 \pm 0.8$ \\
$\quad$ TNF- $\alpha, \mathrm{pg} / \mathrm{ml}$ & $42 \pm 18$ & $60.0 \pm 32^{\mathrm{a}}$ & $12 \pm 6$ \\
Antioxidant activity & & & \\
$\quad$ Total, mmol/l & $3.6 \pm 1.4$ & $1.8 \pm 1.2^{\mathrm{b}}$ & $8.4 \pm 2.4$ \\
$\quad$ SOD, mmol/l & $0.8 \pm 0.4$ & $0.8 \pm 0.4$ & $3.1 \pm 1.1$ \\
$\quad$ GPX, mmol/l & $2.1 \pm 0.8$ & $1.6 \pm 0.8$ & $4.2 \pm 2.2$ \\
Trace elements (mean) & & & \\
$\quad$ Cadmium, $\mu \mathrm{g} / \mathrm{ml}$ & 1.8 & 1.8 & 1.7 \\
$\quad$ Magnesium, $\mu \mathrm{g} / \mathrm{ml}$ & 98 & 101 & 96 \\
$\quad$ Selenium, $\mu \mathrm{g} / \mathrm{ml}$ & 41 & 40 & 44 \\
$\quad$ Zinc, $\mu \mathrm{m} / \mathrm{ml}$ & 168 & 166 & 171 \\
Antisperm antibodies, $\%$ & 10 & 12 & $44^{\mathrm{c}}$ \\
Bcl-2 proteins $(\mathrm{mean})^{\mathrm{d}}$ & & & \\
$\quad$ Bcl-2, $\mathrm{pg} / \mathrm{ml}$ & 212 & 198 & 386 \\
\hline
\end{tabular}

MDA = Malone dialdehyde; SOD = superoxide dismutase; GPX = glutathione peroxidase. Statistical analysis: ANOVA and linear regression analysis.

${ }^{a}$ Asthenozoospermia vs. oligozoospermia, $\mathrm{p}<0.05$; vs. normozoospermia, $\mathrm{p}<0.01$.

${ }^{\mathrm{b}}$ Asthenozoospermia vs. oligozoospermia, $\mathrm{p}<0.05$, and vs. normozoospermia, $\mathrm{p}<0.01$.

${ }^{c}$ Asthenozoospermia vs. normozoospermia, $\mathrm{p}<0.05$.

${ }^{\mathrm{d}}$ Asthenozoospermia vs. normozoospermia, $\mathrm{p}<0.05$ and $\mathrm{p}<$ 0.01 , respectively. 
Table 3. Effects of zinc and antioxidant therapy on seminal and sperm parameters

\begin{tabular}{|c|c|c|c|c|c|c|c|c|c|c|c|}
\hline \multirow[t]{2}{*}{ Semen parameters } & \multicolumn{3}{|l|}{ A } & \multicolumn{3}{|l|}{ B } & \multicolumn{3}{|l|}{$\mathrm{C}$} & \multicolumn{2}{|l|}{$\mathrm{D}$} \\
\hline & 1 & 2 & 3 & 1 & 2 & 3 & 1 & 2 & 3 & 1 & 3 \\
\hline Semen volume, $\mathrm{ml}$ & $4 \pm 2$ & $3 \pm 2$ & $4 \pm 2$ & $3 \pm 2$ & $4 \pm 2$ & $4 \pm 2$ & $3 \pm 2$ & $4 \pm 2$ & $4 \pm 2$ & $4 \pm 2$ & $4 \pm 2$ \\
\hline Sperm count, $\mathrm{m} / \mathrm{m}$ & $46 \pm 22$ & $49 \pm 18$ & $48 \pm 20$ & $44 \pm 16$ & $45 \pm 20$ & $46 \pm 20$ & $45 \pm 23$ & $48 \pm 22$ & $46 \pm 18$ & $46 \pm 16$ & $45 \pm 18$ \\
\hline Motility, \% & $24 \pm 12$ & $36 \pm 14$ & $49 \pm 12$ & $26 \pm 12$ & $39 \pm 16$ & $50 \pm 18$ & $25 \pm 11$ & $40 \pm 14$ & $50 \pm 20$ & $25 \pm 15$ & $24 \pm 12$ \\
\hline Morphology, \% & $69 \pm 16$ & $72 \pm 16$ & $72 \pm 14$ & $70 \pm 15$ & $71 \pm 15$ & $72 \pm 16$ & $70 \pm 16$ & $72 \pm 20$ & $72 \pm 20$ & $70 \pm 16$ & $69 \pm 16$ \\
\hline Teratozoospermia & $29 \pm 11$ & $28 \pm 14$ & $15 \pm 6$ & $30 \pm 18$ & $26 \pm 12$ & $14 \pm 8$ & $29 \pm 14$ & $24 \pm 16$ & $14 \pm 8$ & $29 \pm 11$ & $29 \pm 9$ \\
\hline Sperm membrane integrity & $38 \pm 24$ & $46 \pm 16$ & $56 \pm 15$ & $37 \pm 26$ & $48 \pm 16$ & $60 \pm 20$ & $37 \pm 24$ & $44 \pm 12$ & $56 \pm 20$ & $38 \pm 20$ & $38 \pm 24$ \\
\hline \multicolumn{12}{|l|}{ Oxidative stress } \\
\hline MDA, nmol/l & $9 \pm 3$ & $6 \pm 2$ & $4 \pm 2$ & $9 \pm 3$ & $7 \pm 2$ & $4 \pm 2$ & $10 \pm 3$ & $6 \pm 2$ & $4 \pm 2$ & $9 \pm 3$ & $10 \pm 3$ \\
\hline $\mathrm{TNF}-\alpha, \mathrm{pg} / \mathrm{ml}$ & $58 \pm 32$ & $42 \pm 24$ & $12 \pm 8$ & $60 \pm 34$ & $40 \pm 20$ & $15 \pm 7$ & $58 \pm 28$ & $44 \pm 22$ & $12 \pm 9$ & $60 \pm 32$ & $58 \pm 28$ \\
\hline \multicolumn{12}{|l|}{ Antioxidant status } \\
\hline TAC, mmol/l & $2 \pm 1$ & $6 \pm 2$ & $8 \pm 2$ & $2 \pm 1$ & $6 \pm 2$ & $10 \pm 3$ & $2 \pm 0.8$ & $6 \pm 2$ & $10 \pm 2$ & $2 \pm 0.8$ & $2 \pm 1$ \\
\hline $\mathrm{Zn}-\mathrm{Cu} \mathrm{SOD}$ & $0.8 \pm 0.4$ & $4 \pm 1$ & $5 \pm 2$ & $1 \pm 0.5$ & $3 \pm 1$ & $7 \pm 2$ & $1 \pm 0.5$ & $4 \pm 2$ & $8 \pm 2$ & $1 \pm 0.8$ & $1 \pm 0.5$ \\
\hline GPX & $1.6 \pm 0.8$ & $2 \pm 1$ & $1.6 \pm 0.8$ & $2 \pm 0.8$ & $1.8 \pm 1$ & $1.8 \pm 1$ & $1.8 \pm 1$ & $2 \pm 1$ & $1.8 \pm 1$ & $1.8 \pm 1$ & $1.8 \pm 1$ \\
\hline \multicolumn{12}{|l|}{ Bcl-2 family } \\
\hline $\mathrm{Bcl}-2, \mathrm{pg} / \mathrm{ml}$ & 198 & 320 & 480 & 200 & 324 & 500 & 198 & 324 & 488 & 196 & 224 \\
\hline Bax, pg/ml & 150 & 90 & 65 & 155 & 88 & 70 & 160 & 85 & 64 & 152 & 155 \\
\hline $\mathrm{Bax} / \mathrm{Bcl}-2$ ratio & 0.8 & 0.3 & 0.14 & 0.8 & 0.3 & 0.14 & 0.8 & 0.3 & 0.13 & 0.8 & 0.7 \\
\hline \multicolumn{12}{|l|}{ ASA } \\
\hline IgA & 2 & 2 & 3 & 2 & 2 & 2 & 2 & 2 & 2 & 3 & 3 \\
\hline IgG & 9 & 7 & 4 & 9 & 6 & 3 & 9 & 6 & 2 & 8 & 9 \\
\hline $\operatorname{IgM}$ & 3 & 3 & 3 & 3 & 2 & 3 & 3 & 2 & 2 & 3 & 3 \\
\hline \multicolumn{12}{|l|}{ THC } \\
\hline IL-4, pg/ml & 2 & 8 & 20 & 2 & 9 & 22 & 3 & 10 & 20 & 2 & 2 \\
\hline TNF- $\alpha /$ IL-4 ratio & 29 & 5 & 0.6 & 30 & 4.4 & 0.7 & 19 & 4.4 & 0.6 & 30 & 29 \\
\hline
\end{tabular}

$\mathrm{A}=$ Zinc only therapy; $\mathrm{B}=$ zinc plus vitamin $\mathrm{E} ; \mathrm{C}=$ zinc plus vitamin $\mathrm{E}$ plus vitamin $\mathrm{C} ; \mathrm{D}=$ control; 1 = pretherapy; $2=6$ weeks into therapy; 3 = post-therapy at 12 weeks or 3 months; $\mathrm{MDA}=$ malone dialdehyde; $\mathrm{TAC}=$ total antioxidant capacity; $\mathrm{SOD}=$ superoxide dismutase; $\mathrm{GPX}=$ glutathione peroxidase; ASA = antisperm antibodies; $\mathrm{THC}=$ T helper cytokines.

As shown in table 3 , the three therapy groups were associated with improvement in sperm parameters: sperm concentration, morphology and teratozoospermia compared to control but the difference did not reach statistical significant level. However, there was more than a twofold improvement in the sperm motility $(\mathrm{p}<0.001)$ and fertilizing capacity $(\mathrm{p}<0.05)$ of the treatment group compared to the control, but no significant differences between the treatment groups. On the whole, there was no difference in the outcome measures between zinc only and zinc with antioxidants. Consequently, the results are given as zinc therapy. Zinc therapy was associated with reduction of malone dialdehyde by twofold $(\mathrm{p}<0.01)$ and TNF- $\alpha$ by about fivefold ( $p<0.001$ ). Conversely, there was enhancement of the antioxidant status in the form of total antioxidant capacity $(\mathrm{p}<0.001)$ and $\mathrm{Zn}-\mathrm{Cu}$ SOD $(\mathrm{p}<0.01)$ but not glutathione peroxidase. Similarly, zinc therapy was associated with increased seminal levels of $\mathrm{Bcl}-2(\mathrm{p}<0.01)$ and decreased expression of Bax $(\mathrm{p}<$
0.05), with significantly decreased Bax/Bcl-2 ratio. Zinc therapy was also associated with decreased titre of antisperm antibodies with IgG $(p<0.05)$. There was enhanced expression of IL-4 ( $p<0.01)$, a T helper 2 anti-inflammatory cytokine and the significantly reduced TNF$\alpha /$ IL-4 ratios $(p<0.001)$ compared to the controls. Improvement in the sperm parameters was already obvious by 6 weeks of therapy and the trend continued up to 12 weeks of zinc therapy.

A typical pattern of acridine orange acid denaturation of sperm DNA, to evaluate sperm DNA fragmentation is shown in figure 1 . The sperm DNA fragmentation index represented the percentage of abnormal sperm out of the number of total sperm counted. As shown in figure 2, HE staining was used for the evaluation of sperm viability and apoptosis. In the in vitro evaluation of the effect of zinc on stress-induced sperm DNA fragmentation and apoptosis, zinc deficiency was significantly associated with increased level of malone dialdehyde $(p<0.01)$, in- 
Fig. 1. Acridine denaturation of ejaculated human sperm. The range is from green (normal sperm, NS) to denatured sperm stained red (RS, sperm DNA fragmentation) with yellow-red (YS) showing moderate denaturation (sperm DNA fragmentation). Acridine orange staining. $\times 100$.
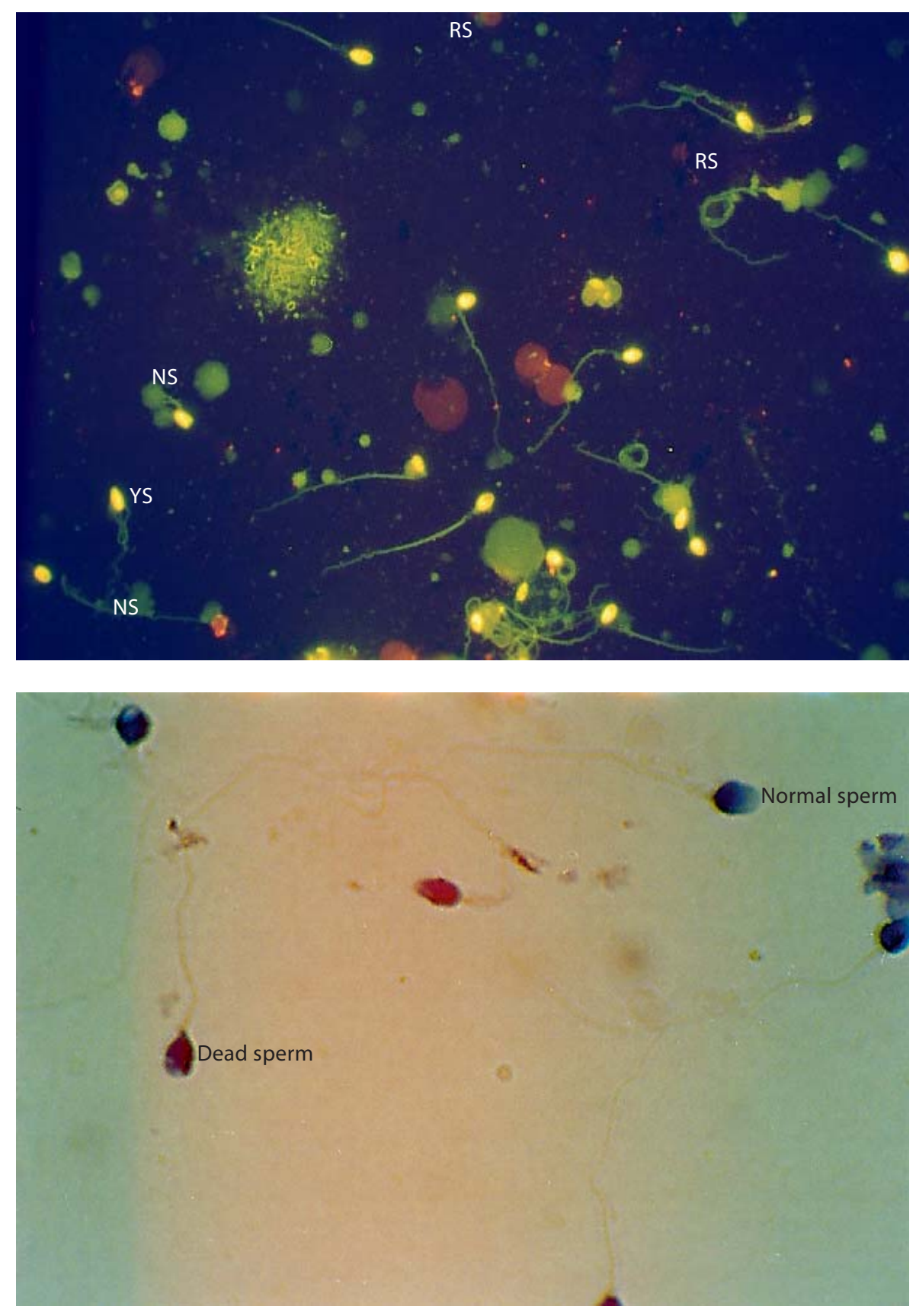

Fig. 2. HE stain of ejaculated human semen showing sperm under light microscopy. Dead sperm with possible extrusion of sperm nucleus. $\times 100$.

creased sperm DNA fragmentation $(\mathrm{p}<0.01)$ and sperm apoptosis $(\mathrm{p}<0.001)$ compared to zinc supplementation and control. There was a strong correlation between the level of malone dialdehyde and sperm DNA fragmentation index $(\mathrm{r}=0.654, \mathrm{p}<0.001)$ and sperm apoptosis $(\mathrm{r}=$ $0.456, \mathrm{p}<0.01)$. Conversely, zinc supplementation was associated with reduced sperm oxidative stress, high sperm membrane integrity, low sperm DNA fragmenta- tion index and level of sperm apoptosis. Electron microscopy of human sperm with structural abnormalities and sperm apoptosis is shown in figure 3. Zinc deficiency was associated with grossly abnormal flagella showing marked hypertrophy and hyperplasia of the fibrous sheath, axonemal disruption and partial defects of the inner dynein arms of microtubular doublets in about 32$34 \%$ of the spermatozoa in the zinc deficiency group 


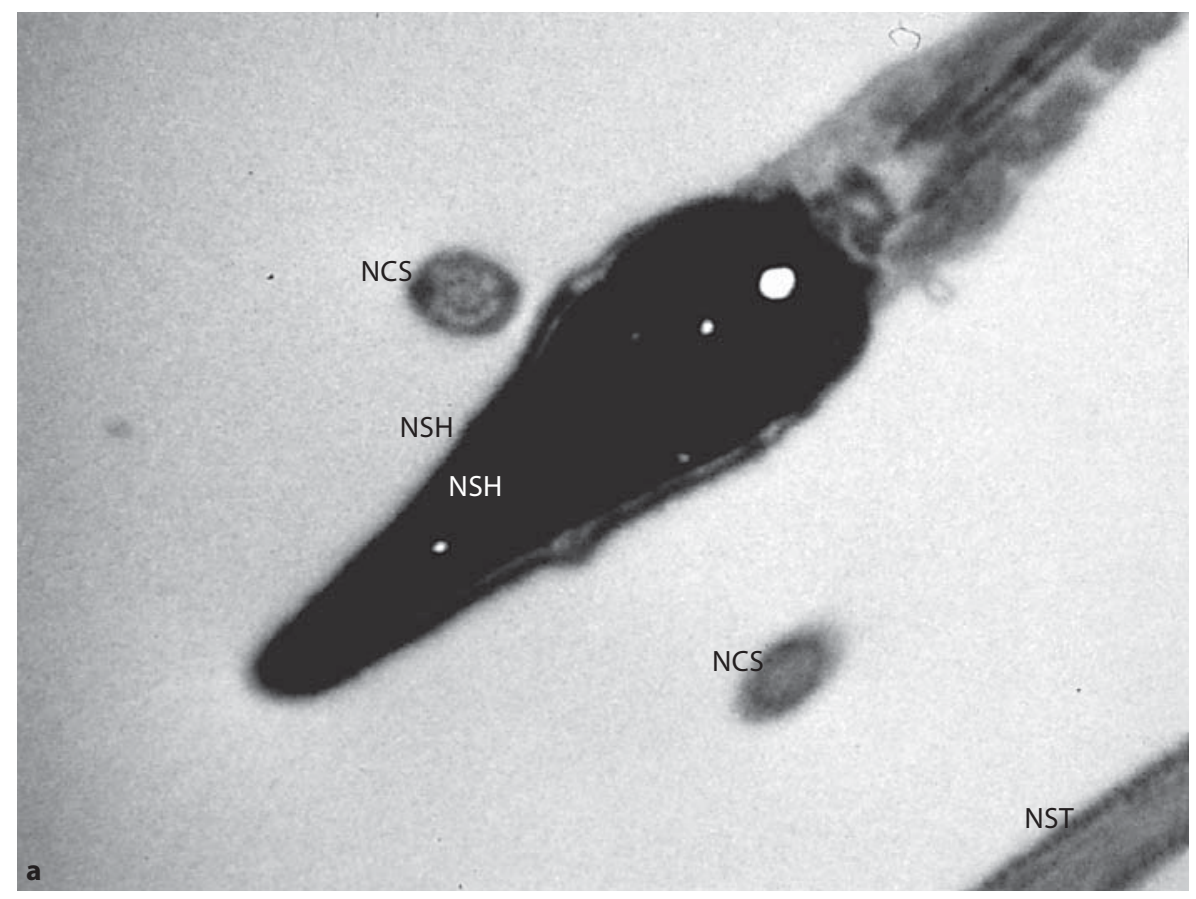

Fig. 3. Transmission electron microscopy. a Patient with normal sperm head (NSH), middle piece with abundant mitochondria and normal tail (NST) and normal cross section (NCS) with 9-2n fibrils. $\times 1,000$. b Severe asthenozoospermia showing increased immature germ cells. EL.S = Elongated spermatid; R $S$ = round spermatid; $\mathrm{S} \mathrm{sp}=$ secondary spermatid.

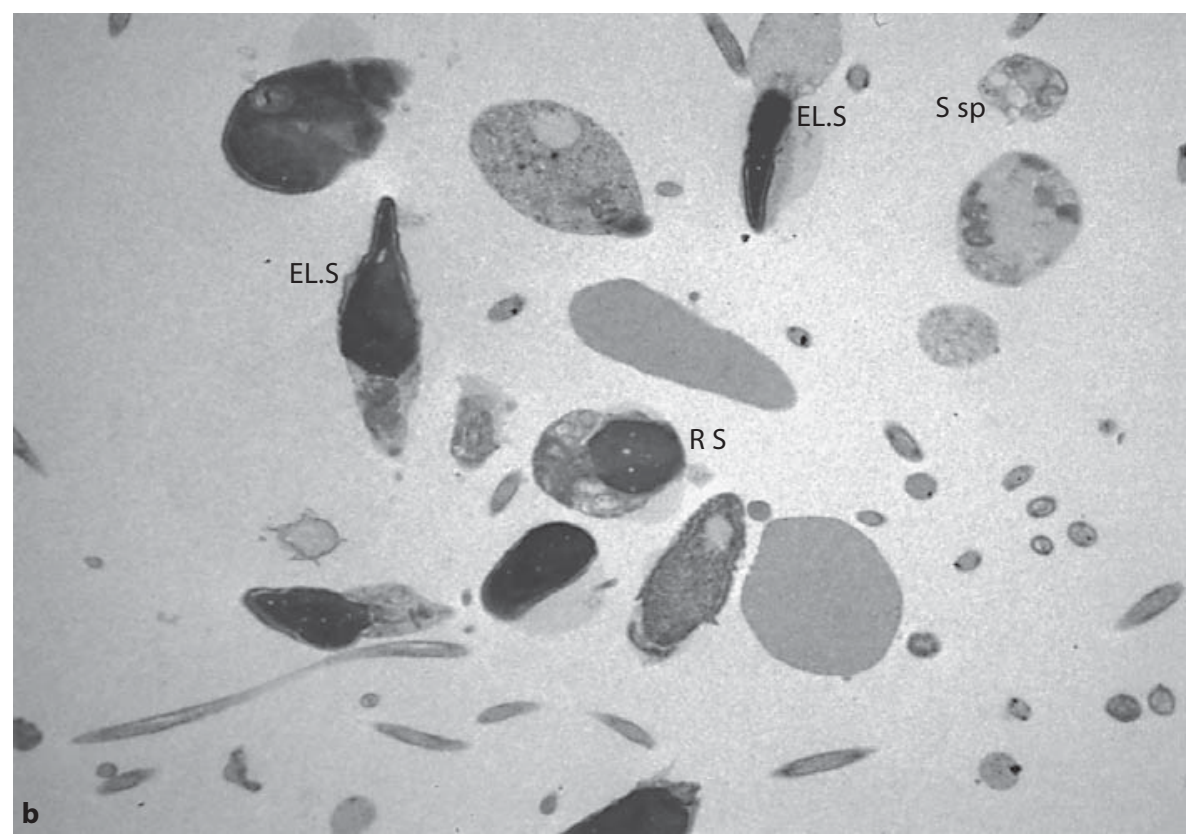

compared to $12-16 \%$ in the zinc supplementation and control groups $(\mathrm{p}<0.05)$. The $9+2$ axonemal structure was completely distorted inside and the middle piece was poorly formed or absent and mitochondria were poorly assembled or absent in $9-18 \%$ of the sperm in the zinc deficiency group compared to $4-8 \%$ in the supplementation and control group $(\mathrm{p}<0.05)$.

\section{Discussion}

The present study has demonstrated that asthenozoospermia is associated with significant levels of seminal oxidative stress with high levels of malone dialdehyde and TNF- $\alpha$, and reduction of sperm membrane integrity, total antioxidant capacity, antisperm antibodies, particularly IgG, and the anti-apoptotic protein $\mathrm{Bcl}-2$. All the

Med Princ Pract 2008;17:108-116 


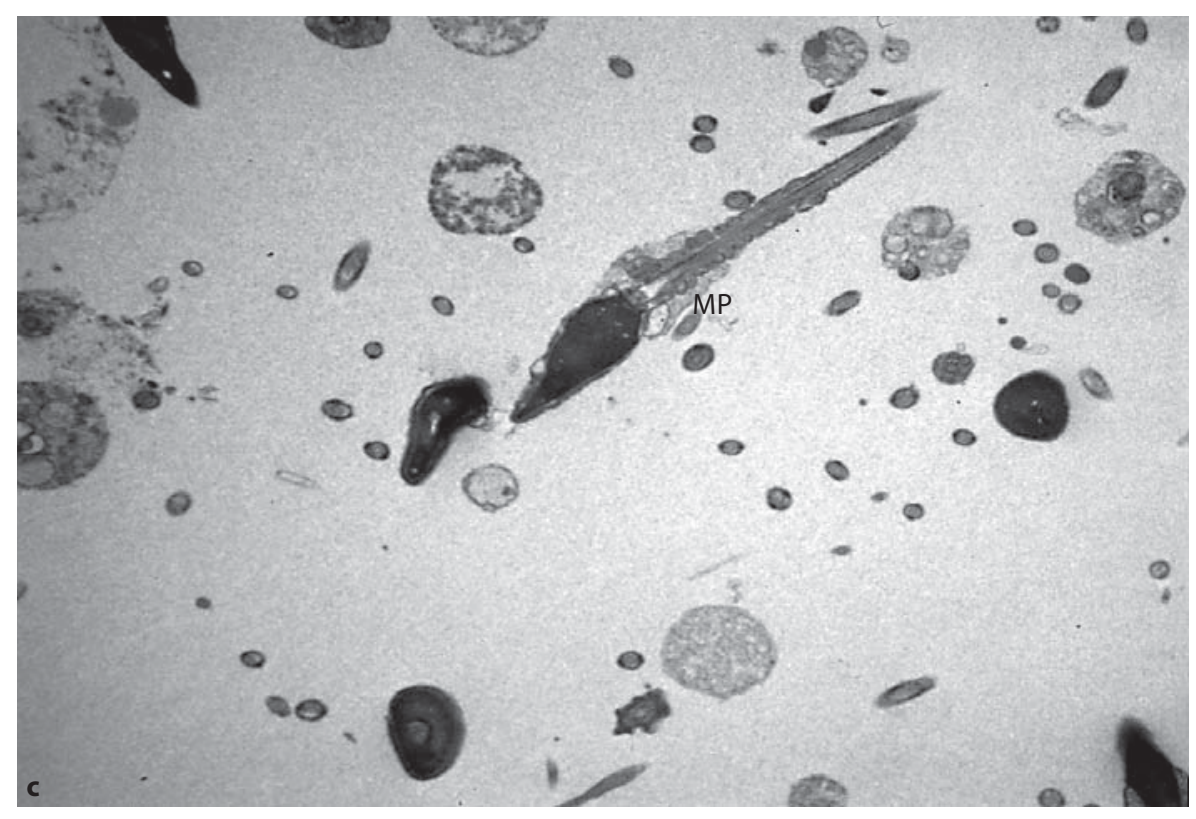

Fig. 3. c In vitro induction of oxidative stress. Disruption of the sperm outer sheath and structural damage of the central core of the axoneme. MP = Middle piece. d In vitro induction of oxidative stress. Increased disruption of sperm fibrous sheath and increased germ cell apoptosis with apoptotic bodies (A. B). $\times 400$.

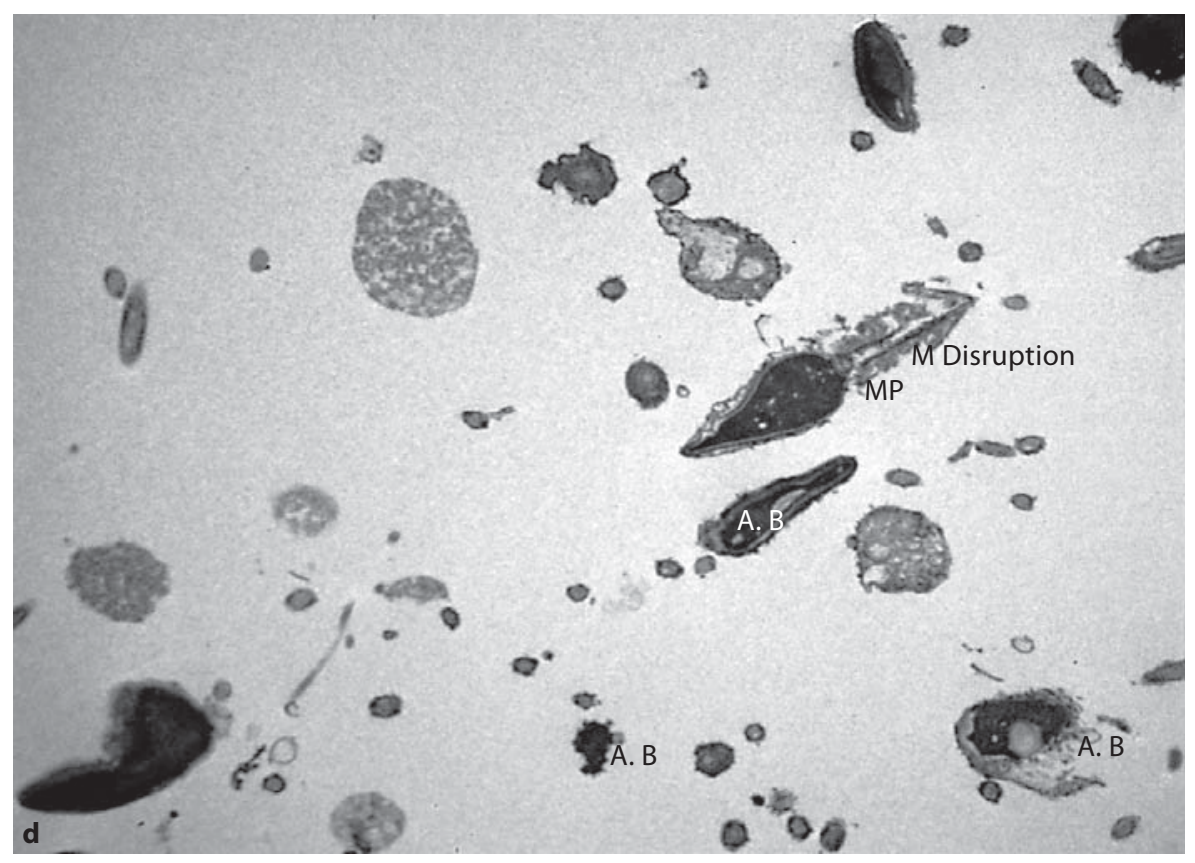

abnormalities except glutathione peroxidase are significantly improved by zinc therapy. Zinc therapy-associated improvement in sperm parameters includes an increase in the seminal antioxidant capacity, reduction of oxidative stress status; increase in $\mathrm{T}$ helper 2 profile and decrease in $\mathrm{T}$ helper 1 cytokine, reduction of antisperm antibody titre, particularly IgG and IgM. There was a reduction of sperm apoptosis through increase in antiapoptotic Bcl-2 and decrease of Bax.
Zinc therapy alone or in combination with chain breaking natural antioxidants such as vitamins $\mathrm{E}$ and $\mathrm{C}$ provide a major source of protection against damaging effects of oxygen radicals, and resulted in improved sperm quality, particularly sperm motility and sperm membrane integrity. As shown in the present study, seminal zinc level does not reflect sperm abnormalities and no method of testing has been identified that is sufficiently sensitive and reproducible to reliably detect indi- 
viduals with zinc deficiency [20]. Superoxide dismutase present in human semen plays a major role in the protection of human spermatozoa against peroxidative damage of its cellular enzymes and structures from reactive oxygen species [21].

There is evidence for a role for $\mathrm{Bcl}-2$ in regulating programmed cell death by functioning as an antioxidant at the outer membrane of the mitochondria by preventing the release of cytochrome c. The levels of pro-apoptotic p53, p21 and bcl-2 family gene expression, and caspase-3 activity in humans are modulated by intracellular zinc status $[8,22]$. The reduction of antisperm antibodies, especially IgG, demonstrated in the present study may increase sperm motility. In a recent review by Fraker [22] antibody-mediated responses that cause increased rates of infections of longer duration are the immunological hallmarks of zinc deficiency. Better understanding of the molecular and cellular response to zinc deficiency could lead to the development of immunotherapeutic interventions.

An important finding in the in vitro induced oxidative stress of this study is the association between zinc deficiency and high level of sperm DNA fragmentation and apoptosis. This is in agreement with earlier studies [23] about the role of apoptosis and reactive oxygen species in inducing sperm DNA damage and apoptosis in both mature and immature spermatozoa in the form of condensation or nuclear maturity defect, DNA integrity defects and chromosomal aneuploidy [24]. Men with sperm DNA damage experience male factor infertility [25].

The electron microscopic findings of abnormalities of sperm axons, mitochondria and dynein arms with zinc deficiency in the present study are of clinical significance. In their study of zinc content of sperm flagella, Henkel et al. [26] demonstrated that the outer dense fibre incorporates a high amount of zinc during spermatogenesis in order to protect the outer dense fibre from premature oxidation. Zinc deficiency during spermatogenesis may therefore cause defective mature sperm motility.

\section{Conclusion}

Zinc therapy improved the spermatozoal quality through possible mechanisms such as increased expression of $\mathrm{Zn}-\mathrm{Cu}$ superoxide dismutase and anti-apoptotic Bcl-2 and reduced Bax, decreased seminal antisperm antibody titres and also decreased sperm DNA fragmentation.

\section{References}

1 Gil-Guzman E, Ollero M, Lopez MC, Sharma RK, Alvarez JG, Thomas AJ Jr, Agarwal A: Differential production of reactive oxygen species by subsets of human spermatozoa at different stages of maturation. Hum Reprod 2001;16:1922-1930.

$\checkmark 2$ Kremer J, Jager S: The significance of antisperm antibodies for sperm-cervical mucus interaction. Hum Reprod 1992;7:781-784.

$\checkmark 3$ Omu AE, Al-Qattan F, Abdulhadi F, Fernandes S: Seminal immune response in infertile men with leukocytospermia: effect on antioxodant activity. Eur J Obstet Gynecol Reprod Biol 1999;79:179-184.

$\checkmark 4$ Oldereid NB, Thomassen Y, Purvis K: Seminal plasma lead, cadmium and zinc in relation to tobacco consumption. Int J Androl 1994; 17:24-28.

5 Omu AE, Al-Othman S, Mohammad AS, AlKaluwby NM, Fernandes S: Antibiotic therapy of seminal infection: effect on antioxidant activity and $\mathrm{T}$ helper cytokines. J Reprod Med 1998;43:857-864.
6 Donnelly ET, McClure N, Lewis SEM: The effect of ascorbate and $\alpha$-tocopherol supplementation in vitro on DNA integrity and hydrogen peroxide-induced DNA damage in human spermatozoa. Mutagenesis 1999;14: 505-511.

7 Chow CK: Vitamin E and oxidative stress. Free Radical Biol Med 1991;11:215-222.

$>8$ Niki E: Action of ascorbic acid as scavenger of active and stable oxygen radicals. Am J Clin Nutr 1991;54:1119S-1124S.

9 Kobayashi T, Miyazaki T, Natori M, Nozawa $\mathrm{S}$ : Protective role of superoxide dismutase in human sperm motility: superoxide dismutase activity and lipid peroxide in human seminal plasma and spermatozoa. Hum Reprod 1991;6:987-991.

10 Wong WY, Merkus HM, Thomas CM, Menkveld R, Zielhuis GA, Steegers-Theunissen RP: Effects of folic acid and zinc sulphate on male factor subfertility: a double-blinded, randomized, placebo-controlled trial. Fertil Steril 2002;77:491-498.
11 Ebisch IM, Pierik FH, De Jong FH, Thomas CM, Steegers-Theunissen RP: Does folic acid and zinc sulphate intervention affect endocrine parameters and sperm characteristics in men. Int J Androl 2006;29:339-345.

12 World Health Organisation: WHO Laboratory Manual for Examination of Human Semen and Semen-Cervical Mucus Interaction. Boston, Cambridge University Press, 1999, pp 2-5.

-13 Omu AE, Dashti H, Mohammed AT, Mattappallil AB: Significance of trace elements in seminal plasma of infertile men. Nutrition 1995;11:502-505.

$\checkmark 14$ Kehinde EO, Mojiminiyi OA, Mahmoud AH, Al-Awadi KA, Al-Hunayan A, Omu AE: The significance of measuring the time course of serum malondialdehyde concentration in patients with torsion of the testis. J Urol 2003;169:2177-2180.

15 Sikka SC: Oxidative stress and role of antioxidants in normal and abnormal sperm function. Front Biosci 1996;1:78-86.

16 Evenson D, Jost L: Sperm chromatin structure assay is useful for fertility assessment. Methods Cell Sci 2000;22:169-189. 
-17 Aitken RJ, Gordon E, Harkiss D, Twigg JP, Milne P, Jennings Z, Irvine DS: Relative impact of oxidative stress on the functional competence and genomic integrity of human spermatozoa. Biol Reprod 1998;59:10371046.

- 18 Olmedo SB, Rawe VY, Nodar FN, Galaverna GD, Acosta AA, Chemes HE: Pregnancies established through intracytoplasmic sperm injection (ICSI) using spermatozoa with dysplasia of fibrous sheath. Asian J Androl 2000;2:125-130.

19 Sandstead H: Is zinc deficiency a public health problem? Nutrition 1995;11:87-92.
20 Fanzo JC, Reaves SR, Cui L, Zhu L, Lei KY: p53 protein levels, cyclin-dependent kinase inhibitor p21, bcl-2 family genes, and caspase- 3 activity are altered by zinc status in aortic endothelial cells. Am J Physiol Cell Physiol 2002;283:C631-C638.

21 Menella MRF, Jones R: Properties of superoxides in metal-ion-catalysed lipid peroxidation reaction in semen. Biochem J 1991; 180:289-297.

22 Fraker PJ: Roles for cell death in zinc deficiency. J Nutr 2005;135:359-362.

23 Moustafa MH, Sharma RK, Thornton J, Mascha E, Abdel-Hafez M, Thomas AJ Jr, Agarwal A: Relationship between ROS production, apoptosis and DNA denaturation in spermatozoa from patients examined for infertility. Hum Reprod 2004;19:129-138.
24 Agarwal A: Relationship between ROS production, apoptosis and DNA denaturation in spermatozoa from patients examined for infertility. Hum Reprod 2004;19:129-138.

25 Wang X, Sharma RK, Sikka SC, Thomas AJ Jr, Falcone T, Agarwal A: Oxidative stress is associated with increased apoptosis leading to spermatozoa DNA damage in patients with male infertility. Fertil Steril 2003;80: 531-535.

26 Henkel R, Bittner J, Weber R, Huther F, Miska W: Relevance of zinc in human sperm flagella and its relation to motility. Fertil Steril 1999;6:1138-1143. 